OPEN ACCESS

Edited by:

Esther Christina De Jong, Academic Medical Center,

Netherlands

Reviewed by:

Peter David Arkwright,

The University of Manchester,

United Kingdom

Meredith Crane,

Brown University, United States

Nina M. Van Sorge,

Amsterdam University Medical Center,

Netherlands

*Correspondence:

Dennis Nurjadi

dennis.nurjadi@uni-heidelberg.de

Specialty section:

This article was submitted to

Microbial Immunology,

a section of the journal

Frontiers in Immunology

Received: 03 December 2021 Accepted: 07 February 2022

Published: 24 February 2022

Citation:

Ngo QV, Faass L, Sähr A, Hildebrand D, Eigenbrod T, Heeg $K$ and Nurjadi D (2022) Inflammatory Response Against Staphylococcus aureus via Intracellular Sensing of

Nucleic Acids in Keratinocytes.

Front. Immunol. 13:828626. doi: 10.3389/fimmu.2022.828626

\section{Inflammatory Response Against Staphylococcus aureus via Intracellular Sensing of Nucleic Acids in Keratinocytes}

\author{
Quang Vinh Ngo ${ }^{1,2}$, Larissa Faass ${ }^{1,3}$, Aline Sähr ${ }^{1}$, Dagmar Hildebrand ${ }^{1}$, \\ Tatjana Eigenbrod ${ }^{1}$, Klaus Heeg ${ }^{1,2}$ and Dennis Nurjadi ${ }^{1,2^{*}}$ \\ ${ }^{1}$ Department of Infectious Diseases, Medical Microbiology and Hygiene, Heidelberg University Hospital, Heidelberg, \\ Germany, ${ }^{2}$ Deutsches Zentrum für Infektionsforschung (DZIF), Department of Infectious Diseases, Heidelberg University \\ Hospital, Heidelberg, Germany, ${ }^{3}$ Max von Pettenkofer Institute, Chair for Medical Microbiology and Hygiene, Ludwig \\ Maximilians University Munich, Munich, Germany
}

Staphylococcus aureus is one of the clinically most relevant pathogens causing infections. Humans are often exposed to $S$. aureus. In approximately one-third of the healthy population it can be found on the skin either for long or short periods as colonizing "commensals", without inducing infections or an inflammatory immune response. While tolerating $S$. aureus seems to be limited to certain individuals and time periods in most cases, Staphylococcus epidermidis is tolerated permanently on the skin of almost all individuals without activating overwhelming skin inflammation. To investigate this, we cocultured a keratinocyte cell line ( $\mathrm{HaCaT}$ ) with viable $\mathrm{S}$. aureus or $\mathrm{S}$. epidermidis to study the differences in the immune activation. S. aureus activated keratinocytes depicted by a profound IL-6 and IL-8 response, whereas S. epidermidis did not. Our data indicate that internalization of $S$. aureus and the subsequent intracellular sensing of bacterial nucleic acid may be essential for initiating inflammatory response in keratinocytes. Internalized dsRNA activates IL-6 and IL-8 release, but not TNF- $\alpha$ or IFNs by human keratinocytes. This is a non-specific effect of dsRNA, which can be induced using Poly(l:C), as well as RNA from S. aureus and S. epidermidis. However, only viable $S$. aureus were able to induce this response as these bacteria and not $S$. epidermidis were actively internalized by $\mathrm{HaCaT}$. The stimulatory effect of $S$. aureus seems to be independent of the TLR3, -7 and -8 pathways.

Keywords: Staphylococcus aureus, Staphylococcus epidermidis, keratinocyte, skin immune response, bacterial RNA, host-pathogen interaction

\section{INTRODUCTION}

The immunology of the human skin is complex. The skin is the largest immune organ of the human body and acts as a physical and immunological barrier against invading pathogens, which can sense invading pathogens and react accordingly $(1,2)$. As a primary response and innate defense mechanism, keratinocytes respond to stimuli, such as trauma and bacterial invasion, by producing antimicrobial peptides (AMP) to eliminate potentially harmful pathogens. 
Although the human skin is constantly exposed to various bacteria as part of the skin microbiome or invading pathogen, some bacteria are tolerated, while others are eliminated. For approximately $20-30 \%$ of the healthy population, Staphylococcus aureus is considered part of their microbiome and colonize their nasal cavity and the skin (3). At the same time, others are transiently colonized and can prevent persistent colonization with S. aureus (4).

The underlying mechanism of $S$. aureus colonization is complex and multifactorial. Potential determinants include bacterial virulence factors (5), the composition of and competition within the nasal microbiome $(6,7)$ and immunological processes involving the skin and the adaptive immunity $(6,8-13)$. However, the link between the innate and the adaptive immune response in this context is not yet fully elucidated. The skin is equipped with an arsenal of pattern recognition receptors (PRRs), which sense conserved microbial structures to initiate innate immune response, and produce proinflammatory cytokines and chemokines, which is essential for leukocyte recruitment and activation of adaptive immune response. Although Staphylococcus epidermidis, commonly regarded as commensals and $S$. aureus as facultative pathogens share similar conserved microbial structures, only about onethird of the healthy population is colonized by S. aureus, whereas S. epidermidis can be found in nearly all individuals $(14,15)$. This observation leads us to the hypothesis that $S$. aureus and $S$. epidermidis induce a differential immune response in the skin, facilitating or preventing persistent colonization.

Classically, the recognition of staphylococci by innate immune cells, such as keratinocytes, is attributed to secreted proteins (e.g. protein A, hemolysins, phenol-soluble modulin (PSM)) and cell wall components (e.g. peptidoglycan and lipoteichoic acid) via the extracellular membrane-bound PRR toll-like receptor 2 (TLR2) (16-19). In S. aureus, TLR2 activation has been demonstrated to depend on PSM-mediated shedding of lipoproteins (20). Of note, species, and strain differences in PSM expression due to chromosomally or extra-chromosomally encoded PSM may have an influence on immune evasion and activation (21). However, since both $S$. aureus and $S$. epidermidis can activate the extracellular TLR2 to initiate the skin's immune response against bacterial invasion and infection $(16,19)$, another mechanisms must be involved in differentiation between $S$. aureus and S. epidermidis. For a long time, S. aureus has been regarded as an extracellular pathogen. The significance of $S$. aureus as an intracellular pathogen has only been acknowledged recently $(22,23)$. Indeed, $S$. aureus can survive and persist within keratinocytes (24-26) and the intracellular presence may have some importance in the pathophysiology of colonization and infection (24). The activation of the intracellular PRR, nucleotide-binding oligomerization domain-containing protein 2 (NOD2) by S. aureus has been demonstrated to be involved in the induction of antimicrobial peptides in keratinocytes (27) and may play a role as a microbial sensor in discriminating between commensal and pathogenic bacteria (28). In contrast, $S$. epidermidis is generally regarded as a non-invasive facultative pathogen, mainly causing superficial and device-associated infections (24).
This study aims to investigate, how keratinocyte can sense and differentiate between commensal and potentially pathogenic staphylococci in an in vitro experimental set up using immortalized keratinocytes.

\section{MATERIALS AND METHODS}

\section{Keratinocyte Cell Culture}

Immortalized keratinocyte cell line HaCaT (DKFZ, Germany) was sustained in proliferative state in a low $\mathrm{Ca}^{2+}\left(0.036 \mathrm{mM} \mathrm{Ca}^{2+}\right)$ DMEM (Invitrogen) supplemented with $10 \%$ fetal bovine serum and $5 \mathrm{mM} \mathrm{L}$-glutamine without antibiotics at $37^{\circ} \mathrm{C}$ with $5 \% \mathrm{CO}_{2}$.

\section{Stimuli and Receptor Ligands}

For the in vitro infection assays, $1 \times 10^{5}$ or $1 \times 10^{6} \mathrm{HaCaT}$ cells were seeded into a 24 -well plate or a 12 -well plate, respectively, and cultured to confluence at $37^{\circ} \mathrm{C}$ with $5 \% \mathrm{CO}_{2}$ for 24 hours. The following stimulating agents were used: lipopolysaccharide (LPS) $0.5 \mu \mathrm{g} / \mathrm{ml}$ (Invivogen), Pam3Cys (P3C) $0.5 \mu \mathrm{g} / \mathrm{ml}$ (EMC microcollections $\mathrm{GmbH}$ ), resiquimod (R848) $5 \mu \mathrm{g} / \mathrm{ml}$ (Enzo Life Sciences $\mathrm{GmbH}$ ), CpG oligodeoxynucleotides (CpG) $1 \mu \mathrm{M}$ (MWG-Biotech AG), polycytidylic acid (Poly(I:C)) $1 \mu \mathrm{g} / \mathrm{ml}$ (Invivogen), peptidoglycan (PGN) $10 \mu \mathrm{g} / \mathrm{ml}$ (Invivogen) and muramyldipeptide (MDP) $5 \mu \mathrm{g} / \mathrm{ml}$.

\section{S. aureus Preparations for Infection Experiments}

Bacterial cultures were maintained in either tryptic soy broth (TSB) (Becton Dickinson) as a liquid culture or on Columbia blood agar plate (supplemented with $5 \%$ sheep's blood). Invasive S. aureus strains USA300 FRP3757, 8325-4 and its isogenic noninvasive fibronectin-binding protein $\mathrm{A}$ and $\mathrm{B}$ (FnBA/B)-deficient mutant $(\Delta f n b A \Delta f n b B$ 8325-4) DU5883, and S. epidermidis (ATCC $\left.{ }^{\circledR} 35894\right)$ were used in the initial experiments of this study. Verification experiments were conducted using additional clinical bacterial isolates; an invasive clinical Staphylococcus argenteus SA147 (a member of the S. aureus complex), an invasive clinical S. aureus SS-11921, a non-invasive clinical S. aureus isolate SA303, and a non-invasive coagulasenegative Staphylococcus lugdunensis HD1. A summary table for all used strains in this study is provided in the Supplementary Table S1. For the infection assay with living staphylococci, bacterial cells cultured in tryptic soy broth were harvested in the mid-log phase, adjusted to a McFarland 3.0 (equivalent of $9 \times 10^{8} \mathrm{CFU} / \mathrm{ml}$ ) and diluted to the desired concentrations. After 2 hours of initial incubation with keratinocytes at $37^{\circ}$ with $5 \%$ $\mathrm{CO}_{2}$, gentamicin and lysostaphin (Genaxxon $\mathrm{GmbH}$, Germany) were added to the co-culture to an end-concentration of $10 \mu \mathrm{g} / \mathrm{ml}$ and $2.5 \mu \mathrm{g} / \mathrm{ml}$, respectively, to ensure optimal removal of extracellular bacteria. After further 22 hours of incubation (for a total of 24 hours of co-culture), the cell supernatant was removed and stored at $-20^{\circ} \mathrm{C}$ until further use. The remaining cells were washed thrice with sterile PBS, resuspended in cell lysis buffer (RNA Mini Kit, Bio\&Sell GmbH, Germany) and stored at $-80^{\circ} \mathrm{C}$ until further use. 
For infection experiments with heat-killed bacteria, S. aureus or S. epidermidis were heat-inactivated at $95^{\circ} \mathrm{C}$ for $60 \mathrm{~min}$. Viability check was performed by plating of $10 \mu \mathrm{l}$ of inactivated bacterial suspension onto Columbia blood agar followed by 24 hours incubation at $37^{\circ} \mathrm{C}$. S. aureus conditioned medium was generated by cultivation of $S$. aureus in DMEM with $10 \%$ FCS without antibiotics supplement for 24 hours under constant agitation (200rpm). After centrifugation at $3000 \mathrm{rpm}$ for 10 minutes, the supernatant was sterile filtered (Millex ${ }^{\circledR}$-GS Filter; $0.22 \mu \mathrm{m}) .50 \% \mathrm{v} / \mathrm{v}$ of bacterial supernatant was used as stimulant. To assess the toxicity of $50 \% \mathrm{v} / \mathrm{v}$ bacterial supernatant, we performed an MTT assay on a titration experiment with $10 \%$, $20 \%, 30 \%, 40 \%$ and $50 \%$ v/v bacterial supernatant. Briefly, $5 \times 10^{4}$ $\mathrm{HaCaT}$ cells (per well) were seeded into 48 well plate and cultured for 1 day at $37^{\circ} \mathrm{C}$ and $5 \% \mathrm{CO}_{2}$. After reaching a confluency of $75 \%$, cells were incubated with different amounts of bacterial supernatants (10-50\%) and was incubated further for another 24 hours. Then, supernatants were removed and CellTiter $96{ }^{\circledR}$ Aqueous One Solution Cell Proliferation Assay Solution (Promega; Walldorf, Germany) was added according to the manufacturer's instructions. After 1 hour of incubation absorbance was measured at $490 \mathrm{~nm}$. Cell viability was normalized to an unstimulated control, expressed as percent (Supplementary Appendix).

\section{Quantification of Intracellular Bacteria}

To quantify internalized bacteria by flow cytometry, bacterial cells were fluorescently stained using carboxyfluorescein succinimidyl ester (CFSE, ThermoFisher Scientific, Germany). Briefly, bacterial cells harvested in the mid-log phase were suspended in PBS with $2 \mu \mathrm{M}$ CFSE were incubated in the dark at $37^{\circ} \mathrm{C}$ under constant agitation of $200 \mathrm{rpm}$ for 20 minutes, followed by several PBS washing steps (3 times). The infection experiment was performed as described above. For quantification, infected keratinocytes with CFSE-labelled bacteria were trypsinized for 10 minutes and resuspended in PBS. Quantification of internalized CFSE-labelled bacterial cells was performed by flow cytometry with a FACS Canto (Becton Dickinson GmbH, Germany) and with the BD FACSDiva software version 8.0.1 (Becton Dickinson $\mathrm{GmbH}$ ). First, a gate was set on living cells (excluding cell debris) in the FSC/SSC display. Then, the gated cells were analyzed for FITC-positivity (y-axis: FITC-signal, $x$-axis: FSC) using the non-infected control as a reference. FITC signal above the defined gate was considered positive. Cell viability was quantified using Annexin $\mathrm{V}$ and propidium iodide staining (ThermoFisher Scientific, Germany). Internalization efficiency was expressed as percent of infected cells (CFSE+) over the gated population in the FITC-forward scatter plot (Supplementary Figure S1). The invasive S. aureus Cowan I and the non-invasive Staphylococcus carnosus TM300 were used as positive and negative control for the flow cytometric analysis, respectively. In parallel, manual colony counting to quantify the bacterial density was performed by serial dilution of cell lysate (with $1 \%$ Triton $\mathrm{X}-100$ ) in sterile $0.9 \% \mathrm{NaCl}$ and plating of $100 \mu$ l lysate on Columbia blood agar. Bacterial density was manually counted after 24 hours of incubation at $37^{\circ} \mathrm{C}$ and was expressed as colony forming unit per ml (CFU/ $\mathrm{ml}$ ). Inhibition of bacterial internalization was performed by the addition of $0.5 \mu \mathrm{M}$ cytochalasin-D one hour prior to infection. The toxicity of $0.5 \mu \mathrm{M}$ cytochalasin-D was determined in a titration assay (Supplementary Figure S2).

\section{Bacterial RNA Preparation for Stimulation}

RNA from bacteria cultured in tryptic soy broth $\left(37^{\circ} \mathrm{C}\right.$ ambient air, constant shaking $200 \mathrm{rpm}$ ) harvested in mid-log growth phase was isolated using the phenol-chloroform extraction method. Briefly, bacterial suspension was homogenized using $0.1 \mathrm{~mm}$ glass beads in a bead beater $(2 \times 30 \mathrm{~s})$ after prior washing and resuspension in Tris-EDTA Buffer. After 30 min of shock frosting at $-80^{\circ} \mathrm{C}$, phenol and chloroform (5:1) were added. The aqueous phase was removed and purified with a column-based RNeasy Kit (Qiagen GmbH, Germany) according to manufacturer's protocol. DNase treatment was performed by DNase I (Roche GmbH, Germany). Finally, RNA quantity and purity were evaluated in Nano Drop 1000 3.8.1 (ThermoFisher scientific). For transfection, RNA was complexed with DOTAP (1 $\mu \mathrm{g}$ RNA with $6 \mu \mathrm{l}$ DOTAP, $3 \mu \mathrm{g}$ and $6 \mu \mathrm{g}$ RNA with $12 \mu \mathrm{l}$ DOTAP) in Opti-MEM for $10-15 \mathrm{~min}$ at room temperature prior to stabilization with $\mathrm{Ca}^{2+}$ free DMEM without antibiotics. To verify the specificity of RNA stimulation, RNA was inactivated by heat $\left(30 \mathrm{~min}\right.$ at $95^{\circ} \mathrm{C}$ ) and RNase A (Promega, Germany) treatment prior to transfection. As an additional control, RNA was inactivated by RNase A 2 hours posttransfection to verify internalization of bacterial RNA.

\section{Quantitative mRNA Cytokine Expression}

To quantify the mRNA expression of genes of interest in $\mathrm{HaCaT}$ cells, RNA was extracted from harvested cells using RNA Mini Kit according to the manufacturer's protocol (Bio\&Sell GmbH, Germany) and transcribed to cDNA (First Strand cDNA Synthesis Kit, Thermo Fisher; USA). RTq-PCR was performed in duplicates using SYBR Green (Nippon Genetics; Germany) on the Step One Plus machine according to the manufacturer's protocol and standard cycling conditions (annealing temperature of $60^{\circ} \mathrm{C}$ ). Primers used in this study are listed in Supplementary Table S2. For keratinocytes, $\beta$-actin served as housekeeping gene.

\section{Quantification of Cytokines in Cell Supernatant by ELISA}

Secretion of various cytokines (IL-6, IL-8, TNF- $\alpha$, IFN- $\alpha$ and IL$1 \beta$ ) in supernatant from the infection experiments of $\mathrm{HaCaT}$ cells were quantified by ELISA in duplicates (BD OptEIA, Becton Dickinson, Germany) according to the manufacturer's instructions. ELISA were performed on supernatants, which has been frozen at $-20^{\circ} \mathrm{C}$.

\section{Western Blot}

After infection, keratinocytes were lysed in RIPA buffer. Equal amounts of the lysates were fractioned by SDS-PAGE and electro-transferred to nitrocellulose membranes (neoLab; Heidelberg, Germany). The membranes were blocked with BlueBlock (Serva; Heidelberg, Germany) and incubated with antibodies against RIG-I and MDA-5 (1:1000 overnight; Cell 
Signaling; Frankfurt am Main, Germany). Detection was visualized by enhanced chemiluminescence (ECL; 7Bioscience; Neuenburg am Rhein, Germany) using a ChemoStar Plus Imager (Intas; Göttingen, Germany).

\section{Quantification of Protein Bands in Western Blots}

8-bit JPEG images were black/white inverted, and bands were quantified via ImageJ software version 1.530. In ImageJ the image was adjusted to a background of 0 . Then integrated density (IntDen) of each band of interest was quantified by using equal areas for gating. Data were analyzed by GraphPad Prism v9 (USA). The IntDen of protein band of interest was divided through IntDen of the respective houskeeping protein band. For calculation of induction mean of data of three unstimulated samples were set to 100 percentage.

\section{Statistical Analysis}

Visualization of experiment results and statistical analysis were conducted with GraphPad Prism (version 9.0, GraphPad Software Inc, USA). Group comparisons and statistical significance of differences between observations were assessed by two-wayANOVA or Wilcoxon rank sum test for nonparametric variables as deemed suitable. All experiments were performed in biological triplicates and technical duplicates for each biological replicate. Data presented are summaries of at least three biological replicates, performed as independent experiments. P-values of $<0.05$ were considered statistically significant.

\section{RESULTS}

\section{Differential IL-6 and IL-8 Response by Staphylococcus aureus and Staphylococcus epidermidis in Keratinocytes}

To investigate whether keratinocytes react differently to $S$. aureus and $S$. epidermidis, we co-cultured keratinocytes with $S$. aureus (USA300) or S. epidermidis (MOI 10 or MOI 100). The next day supernatant was analyzed for secreted inflammation factors.

IL-6 and IL-8 were the most prominent and significantly upregulated cytokines detected by ELISA in the 24-hour supernatant (2-hour co-culture with viable bacteria and another 22-hour after addition of gentamicin/lysostaphin) following stimulation with viable $S$. aureus (USA300) but were not detected after stimulation with $S$. epidermidis (Figure 1A) IL- $1 \beta$ and TNF- $\alpha$ were not detected in the supernatants (data not shown). There were no significant differences in the induction of antimicrobial peptides of the skin, human betadefensins (hBD-) 1 to 3, between S. epidermidis and S. aureus (Supplementary Figure S3). In S. aureus, the secreted IL-6 and IL-8 levels were dose-dependent and were more profound in co-culture experiments with MOI 100 than MOI 10. There were no significant differences in the proportion of viable cells (Annexin V/Propidium Iodide staining) after stimulation with USA300 and S. epidermidis (Supplementary Appendix and Supplementary Figure S4).

\section{Internalization of Bacterial Cells Correlates With IL-6 and IL-8 Response}

Having confirmed the differential activating ability of USA300 S. aureus (FPR3757) and S. epidermidis (ATCC ${ }^{\circledR}$ 35894) used in this study, we then investigated possible reasons for this observation. Both staphylococci can activate the extracellular TLR2 to initiate the skin's immune response against bacterial invasion and infection $(16,19)$. However, while $S$. aureus can survive and persist within keratinocytes (24-26), S. epidermidis is generally regarded as a non-invasive facultative pathogen (24). Therefore, we next investigated whether the intracellular localization of $S$. aureus and $S$. epidermidis may explain the observed differential IL-6 and IL-8 response.

For this purpose, we analyzed internalized bacteria using fluorescent (CFSE)-labelled staphylococci by flow cytometry and manual colony counting. After co-culture with CFSElabelled S. aureus (USA300) or S. epidermidis (MOI 10 or MOI 100) for 2 hours, gentamicin and lysostaphin was added and washed multiple times with PBS to kill and remove extracellular bacteria. CFSE signal of internalized bacteria was quantified by flow cytometry (Figures 1B, C). A representative dot blot in Figure 1C as well as the associated quantification shows that a large proportion of keratinocytes internalized $S$. aureus (mean MOI $10=28.8 \%$ and MOI $100=47.0 \%$ ), whereas significantly less cells (mean MOI $10=0.8 \%$ and MOI $100=5.1 \%$ ) contained $S$. epidermidis. Thus, the internalization of bacteria correlated with induced cytokine release (Figure 1A). The results of the manual colony counting are summarized in the Supplementary Appendix and Supplementary Figure S5.

To confirm this correlation, we repeated the experiments using invasive and non-invasive isogenic strains of $S$. aureus 8325-4 and DU5883. S. aureus DU5883 is a fibronectin-binding protein A and B deficient mutant of $S$. aureus 8325-4 (8325-4 $f n b A B)$, which has been shown to have reduced invasive properties (29). Supplementary Figure S1 and Figure 1D confirms that noninvasive DU5883 was only marginally detected in the high MOI of 100 inside of cells. Invasive 8325-4 could be detected in around $20 \%$ at MOI 10 and around $40 \%$ at MOI 100. Quantification of IL-6 and IL- 8 by ELISA showed indeed that invasive $S$. aureus $8325-4$ induced IL-6 and IL-8, whereas the non-invasive $\triangle f n b A B$ mutant did not (Figure 1E), thus confirming the correlation between invasion and keratinocyte activation.

Furthermore, inhibition of bacterial internalization by heat inactivation and inhibition of the actin polymerization, that is needed for bacterial invasion (30), using Cytochalasin-D significantly reduced cytokine release into the co-culture (Figure 2A). We also excluded that secreted bacterial components are responsible for keratinocyte activation and stimulated cells with $S$. aureus supernatant. In our experimental set-up, $50 \% \mathrm{v} / \mathrm{v}$ of bacterial supernatant was used. The highest nontoxic concentration of supernatant $(50 \% \mathrm{v} / \mathrm{v})$ was chosen after titration and MTT cell viability assay (31) to closely mimic the abundance of proteins and cellular products in the viable bacteria 


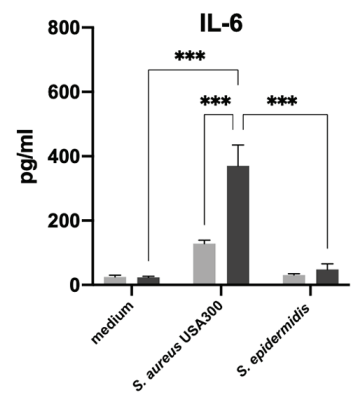

D

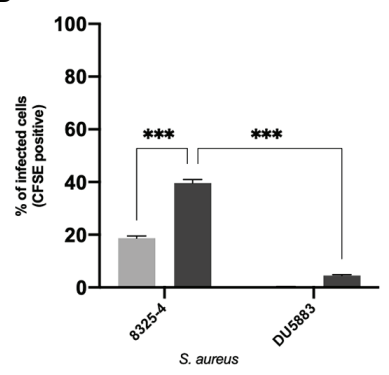

B

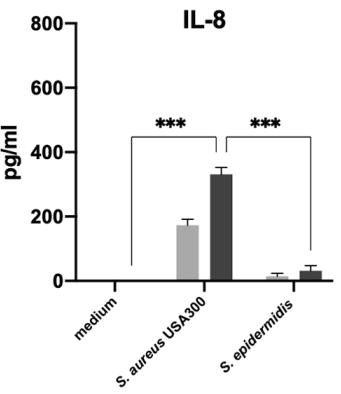

E

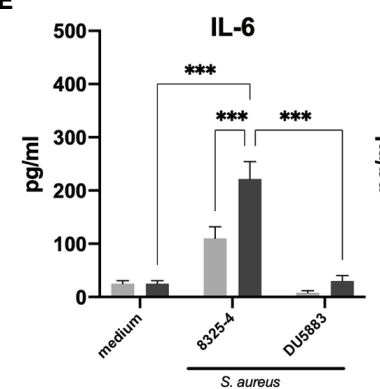

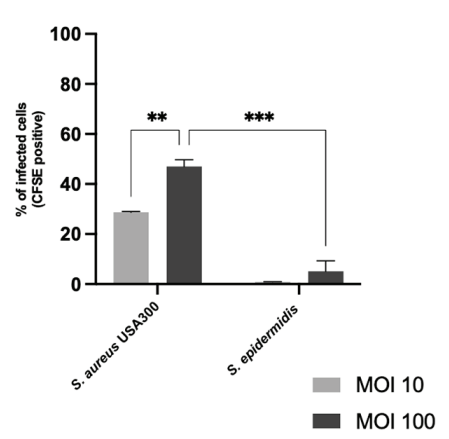

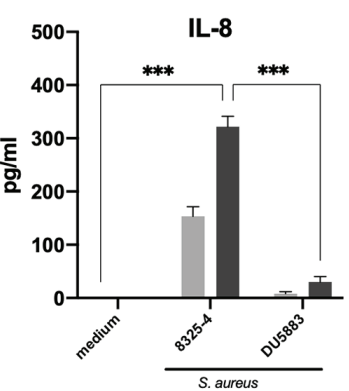

C
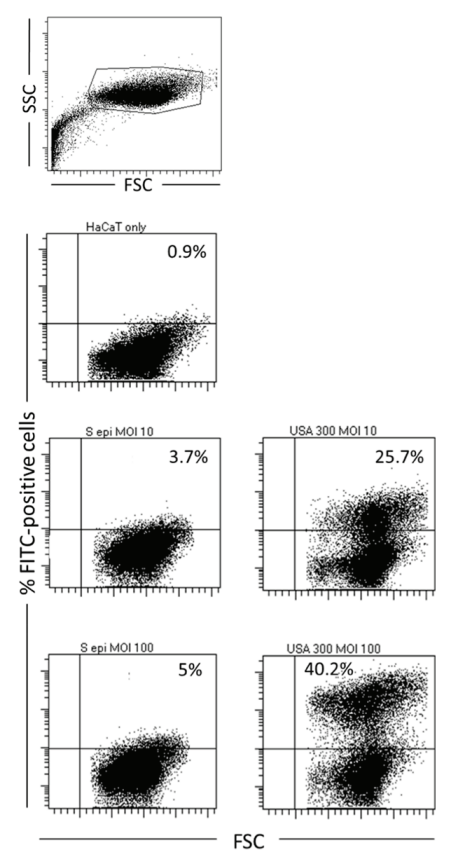

FIGURE 1 | IL-6 and IL-8 response in keratinocytes stimulated with viable Staphylococcus aureus and Staphylococcus epidermidis. (A) S. aureus induced significantly more IL-6 and IL-8 than S. epidermidis in a dose-dependent manner, which correlated with the amount of internalized bacterial cells following 24 hours exposition in a gentamicin/lysostaphin protection assay. (B) Internalized bacteria were quantified by flow cytometry (CFSE positivity). (C) Representative experiment of flow cytometry quantification of bacterial internalization. (D) To confirm the importance of internalized bacterial cells in inducing IL-6 and IL-8 in our experimental setting, we performed the infection assay with an invasive S. aureus strain 8325-4 and the non-invasive isogenic strain S. aureus DU5883 with deletions in the fibronectin binding protein genes fnbA and $f n b B$ ( $\triangle$ fnbAB 8325-4). (E) The deletion mutant induced significantly lower IL-6 and IL-8 compared to the wild type. For panels (A, B, D, E), grey bars indicate $\mathrm{MOI} 10$ and black bars indicate $\mathrm{MOI} 100$. All experiments were performed as independent experiments in biological triplicates, each in technical duplicates. Statistical significance was calculated using two-way ANOVA. Only statistically significant differences $\left({ }^{* *} \mathrm{p} \leq\right.$ $\left.0.01,{ }^{* \star *} \mathrm{p} \leq 0.001\right)$ are displayed.

co-culture set-up (Supplementary Figure S6). The subsequent experiment showed that stimulation with bacterial conditioned medium (BCM) did not induce IL-6 nor IL-8 response, indicating that cellular contact is essential (Figures 2B, C).

\section{Pro-Inflammatory Response of Keratinocytes to Invading Bacteria Is RNA-Mediated and Species Non-Specific}

Since the internalization of bacterial cells was a prerequisite for the induction of the IL- 6 and IL-8 response in our experimental set-up, we then investigated whether the activation of intracellular pathogen-sensing receptors might be involved in initiating immune response towards invasive staphylococci.

Host eukaryotic cells are able to sense danger signals via various intracellular receptors. In the endosome, nucleic acid (RNA) can be recognized by TLR3, TLR7 and TLR8, while TLR9 recognized the unmethylated cytidine-phosphate-guanosine (CpG) motifs in bacterial DNA $(32,33)$. TLR3 senses doublestranded RNA (dsRNA) (34), whereas TLR7 and TLR8 sense degradation products of single-stranded RNA (35). In the cytosol, the key sensors for RNA recognition are RIG-I and MDA5, two helicases of the $\mathrm{DExD} / \mathrm{H}$ motif family, which sense dsRNA (36). Therefore, we next investigated whether various
PRR ligands can activate keratinocytes and mimic the initial findings of the co-culture with viable bacteria. We stimulated $\mathrm{HaCaT}$ cells using various PRRs ligands, namely Pam3Cys for TLR1/2, Poly(I:C) for TLR3, LPS for TLR4, R848 for TLR7/8, CpG for TLR9 and a nucleotide-binding oligomerization domain-containing protein 2 (NOD-2) ligand. Interestingly, only the TLR3-activator Poly(I:C) induced a significant IL-6 and IL-8 response (Figure 3A). This led us to the hypothesis that the observed S.aureus-stimulated activation of keratinocytes may be mediated by bacterial RNA in the intracellular compartment.

To verify this hypothesis, we isolated total RNA from the invasive $S$. aureus USA300 and the non-invasive/noninternalized S. epidermidis in the logarithmic growth phase and performed titration experiments by transfecting $1 \mu \mathrm{g}, 3 \mu \mathrm{g}$ and $6 \mu \mathrm{g}$ of the bacterial RNA using the liposomal transfection reagent DOTAP. Indeed, we observed a dose-dependent IL-6 and IL-8 response (Figure 3B and Supplementary Figure S7) for both S. aureus USA300 and S. epidermidis. Of note, although the co-culture with S. epidermidis at MOI 100 did not induce IL6 response, the transfected RNA was able to induce significant IL-6 and IL- 8 response. For the invasive $S$. aureus USA300, $3 \mu \mathrm{g}$ RNA could induce a similar IL-6 response as infection with viable bacteria at MOI 100. 


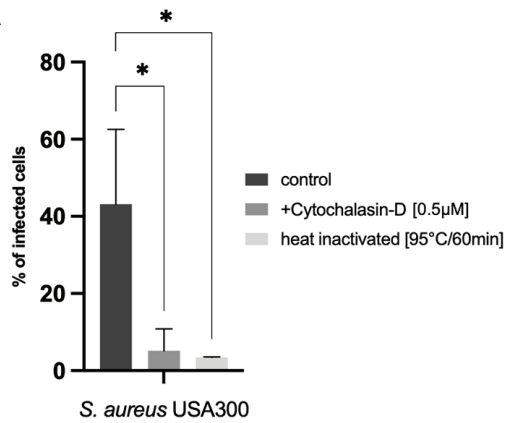

C

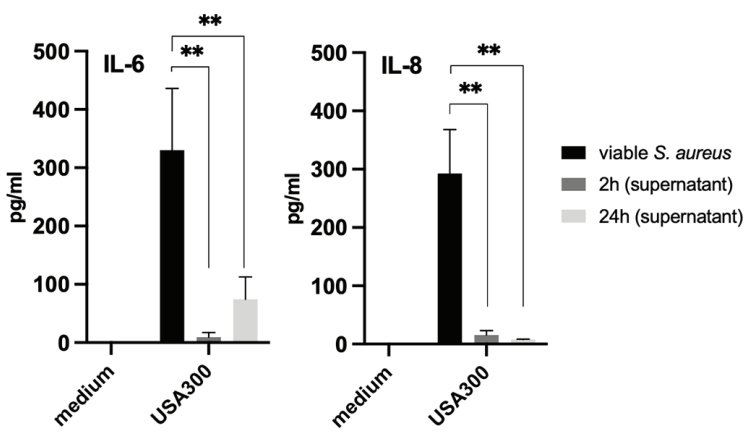

B
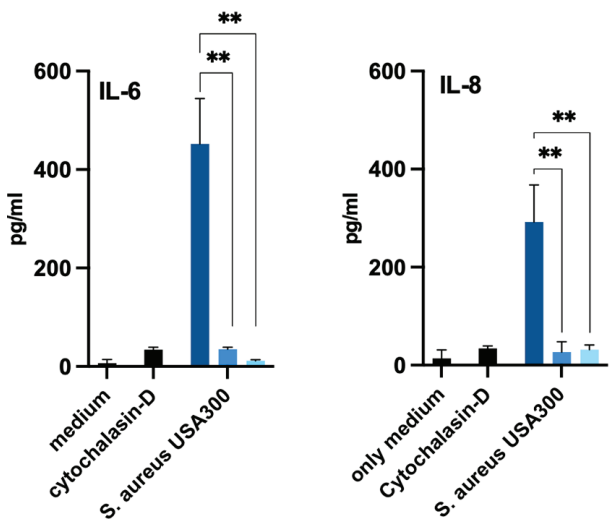

viable $S$. aureus

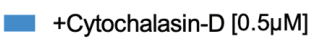

heat inactivated $\left[95^{\circ} \mathrm{C} / 60 \mathrm{~min}\right]$

- control

FIGURE 2 | Internalized bacteria and cellular contact are necessary to induce IL-6 and IL-8 in keratinocytes. (A) Inhibition of bacterial cell internalization (MOI 100) using cytochalasin-D as well as heat inactivation of bacterial cells reduced the number of internalized bacteria and (B) diminished both IL-6 and IL-8 response in our experimental set-up. (C) Stimulation using 50\% (V/V) bacterial supernatant, acquired by culturing bacteria in liquid culture for 2 and 24 hours, did not induce IL-6 or IL-8 significantly. All experiments were performed as independent experiments in biological triplicates, each in technical duplicates. Statistical significance was calculated using Wilcoxon rank sum test. Only statistically significant differences $\left({ }^{*} \mathrm{p}<0.5,{ }^{* *} \mathrm{p} \leq 0.01\right.$ ) are displayed.

To verify if the response was RNA-mediated and was not due to other structures (proteins, polysaccharides, and other cellular structures), we performed RNA inactivation experiments with the RNA of $S$. aureus USA300 (Figure 3C). Degradation of bacterial RNA by heat $\left(95^{\circ} \mathrm{C}\right.$ for 30 mins) and RNase treatment $\left(60^{\circ} \mathrm{C}\right.$ for 1 hour) prior to transfection abolished the IL-6 response, whereas DNase treatment had no significant effect (IL-6 response was not abolished), which suggests that DNA sensing was not responsible for the induction of proinflammatory response following bacterial internalization by keratinocytes. Furthermore, RNase treatment 2 hours posttransfection did not abolish the IL-6 response, thus confirming that internalized bacterial RNA and not extracellular RNA was responsible for the observed IL-6 response (Figure 3C). We verified this finding with the isogenic $S$. aureus isolates 8325-4 and its $\triangle f n b A B$ mutant, DU5883. Similar to S. epidermidis, DU5883 did not demonstrate remarkable induction of IL-6 in $\mathrm{HaCaT}$ cells, but the experimentally transfected RNA induced similar IL-6 response as the invasive isogenic counterpart (8325-

4) (Figure 3B).

Similar results were obtained for IL-8 (Supplementary Figure S7). Thus, the results of our experiments so far suggest that bacterial RNA in the intracellular compartment may be responsible for inducing pro-inflammatory response in invasive staphylococci.

\section{Verification of Findings Using Other Invasive and Non-Invasive Clinical Staphylococci}

To further verify our findings, we repeated identical experiments (co-culture with MOI 100 of viable bacteria and bacterial RNA transfection) with other clinical staphylococci isolates. For this purpose, we selected an invasive clinical $S$. aureus isolate from a skin and soft tissue infection (S. aureus SS-11291), an invasive clinical Staphylococcus argenteus SA147 [a member of the S. aureus complex, formerly classified as S. aureus ST2250 (37, 38)], a non-internalized clinical S. aureus (SA303) from a skin and soft tissue infection and a non-internalized clinical Staphylococcus lugdunensis HD1 (considered as coagulasenegative staphylococci) (39). In concordance to our initial findings, both invasive isolates, SS-11291 and SA147, induced IL-6 and IL-8 response at MOI 100, whereas the non-invasive isolates, SA303 and HD1, did not (Figures 4A-C). More importantly, transfection of bacterial RNA of the non-invasive SA303 and HD1 induced both IL-6 and IL-8, which was abolished 
A
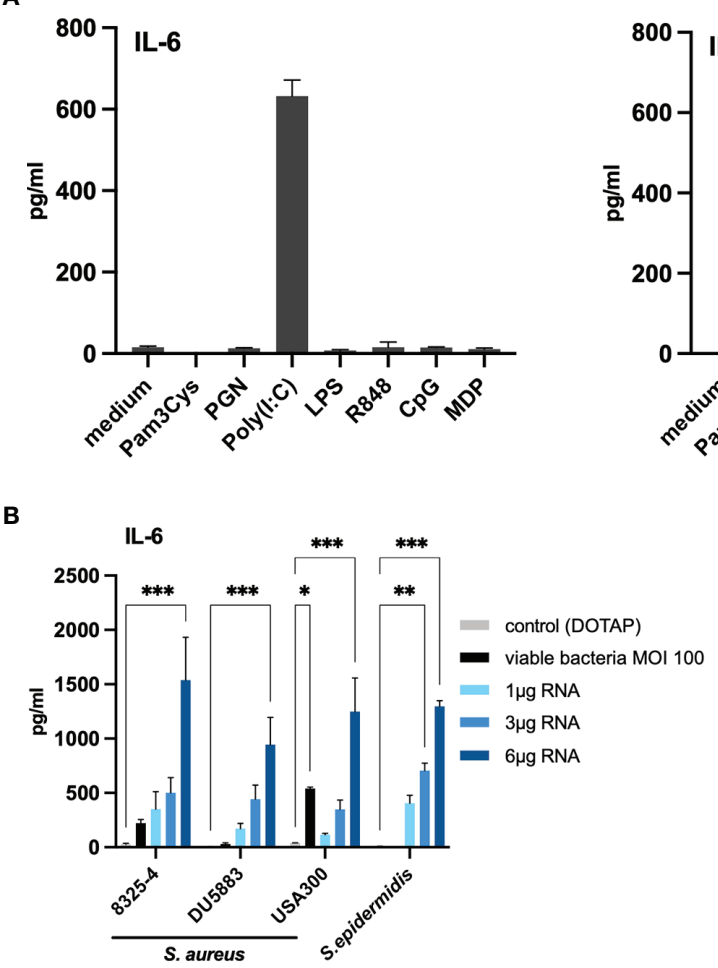

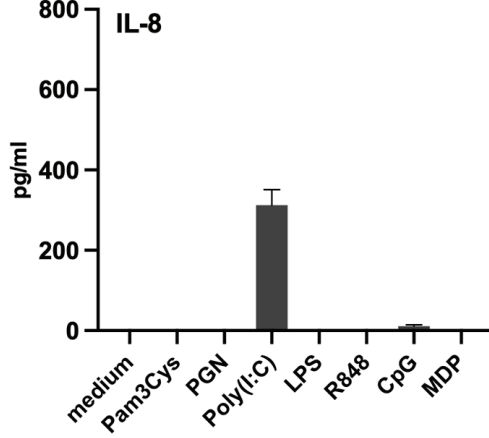

C

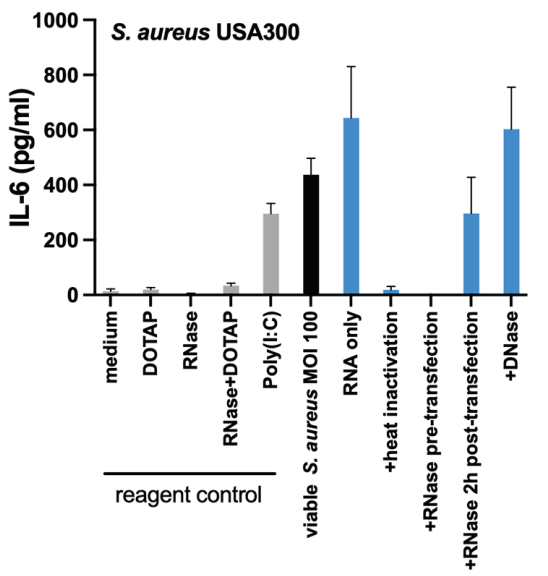

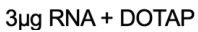

FIGURE 3 | Transfection of bacterial RNA from non-invasive staphylococci induced IL-6 in a similar manner to invasive living bacteria. (A) Stimulation with various pattern recognition receptor ligands indicated that TLR3/dsRNA induces IL-6 and IL-8 response in HaCaT keratinocytes. (B) Transfection of bacterial RNA isolated from the non-invasive S. aureus DU5883 and S. epidermidis induced IL-6 in a dose-dependent manner similar to invasive S. aureus strains (USA300, 8325-4). (C) RNA inactivation (heat and RNase treatment) prior to transfection diminished the IL-6 response, while RNase treatment 2 hours post transfection did not. There was no effect on the IL-6 induction following DNase treatment suggesting that internalized bacterial RNA is responsible for the IL-6 response. Data for IL-8 are available in the Supplementary Appendix. All experiments were performed as independent experiments in biological triplicates, each in technical duplicates. Statistical significance was calculated using two-way ANOVA. Statistically significant differences are indicated by ${ }^{*}\left({ }^{*} p<0.5,{ }^{* *} p \leq 0.01,{ }^{* \star *} p \leq 0.001\right)$.

upon RNase treatment prior to transfection (Figure 4D and Supplementary Figure S7).

\section{RNA in the Cytoplasm Is Responsible for the Pro-Inflammatory Response Following Bacterial Internalization}

Eukaryotic cells are equipped with both endoplasmic and cytoplasmic RNA sensors. In order to identify, which receptors may be involved in the recognition of bacterial RNA following bacterial internalization, we performed inhibition experiments using various PRR inhibitors. First, we inhibited the endosomal PRRs (TLR3, TLR7, TLR8 and TLR9) using bafilomycin and chloroquine (40), and Poly(I:C) (TLR3 ligand) as a positive control. The addition of $20 \mathrm{nM}$ bafilomycin and $25 \mu \mathrm{M}$ chloroquine were able to inhibit Poly(I:C) mediated induction of IL- 6 and IL- 8 , but not the immune response towards viable bacteria of MOI 100 (Figure 5A). Therefore, it is unlikely that endosomal TLRs are largely involved in the sensing of internalized bacterial RNA in our experimental set-up.

The next step would be to inhibit the cytoplasmic RNA sensors, MDA5 and RIG-I. However, since specific inhibitors for RIG-I and MDA5 were not commercially available, we were not able to perform inhibition experiments for MDA5 and RIG-I receptors. As an alternative, we resort to protein expression level analysis using RT-qPCR and specific antibodies for MDA5 and RIG-I by Western Blot (Figures 5B, C and Supplementary Figure S8). Stimulation with viable $S$. aureus induced more RIG-I and MDA5 compared to stimulation with S. epidermidis, which was in line with the IL-6 and IL-8 response. Experimental attempt to inhibit the expression of MDA5 and RIG-I using siRNA was unsuccessful due to the cell toxicity effect at higher concentrations and non-significant inhibition at non-toxic concentrations. 

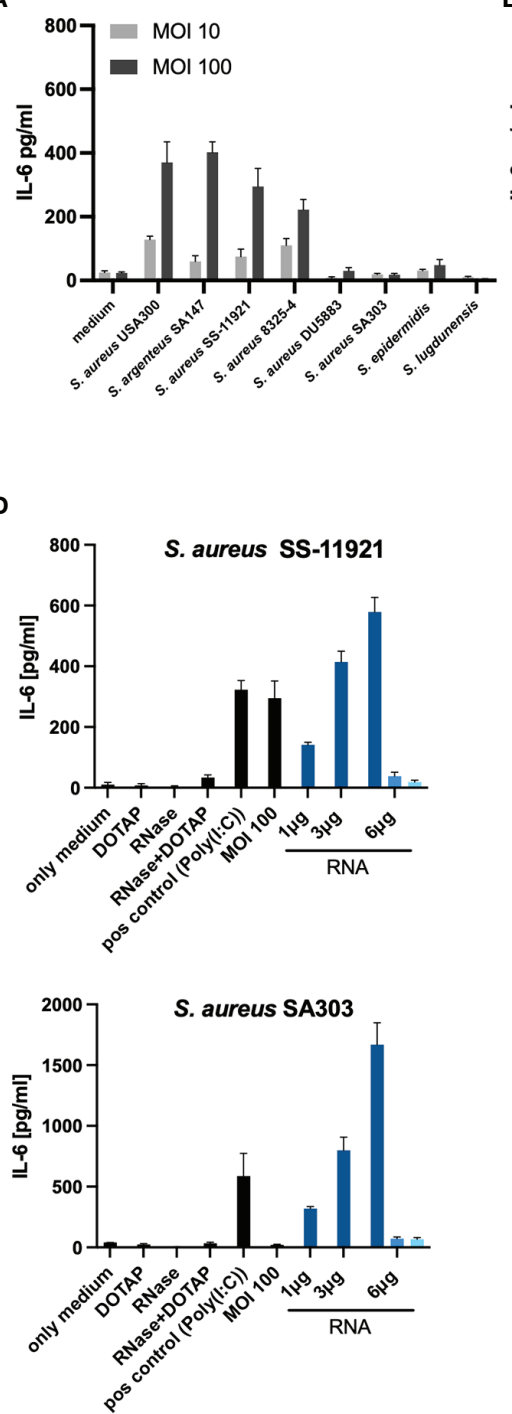

B

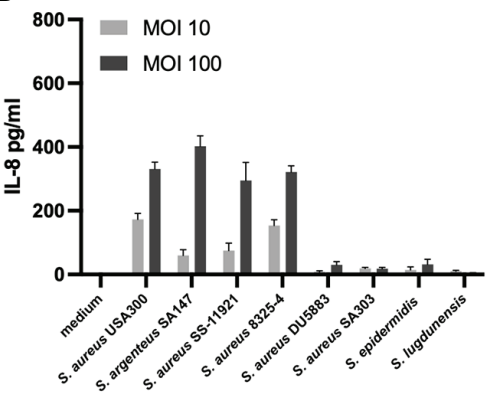

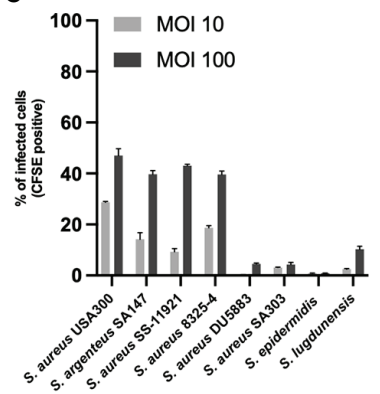
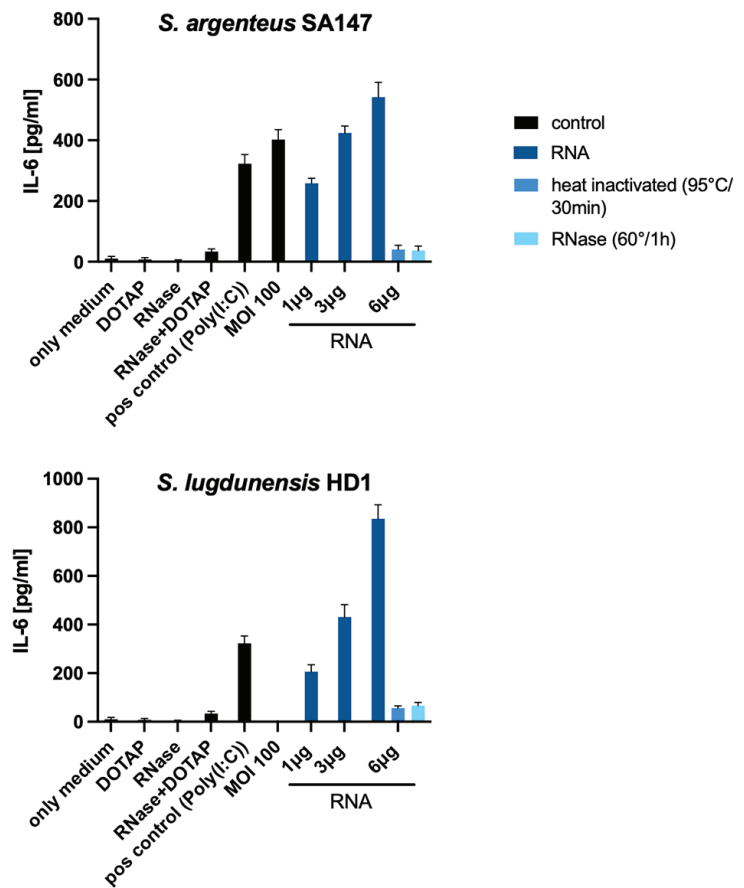

FIGURE 4 | Validation of IL-6 and IL-8 response due to internalized bacterial RNA using clinical staphylococci isolates. To validate our initial findings, we repeated the experiments using four clinical staphylococci isolates; an invasive S. aureus clinical isolate SS-11921, an invasive Staphylococcus argenteus SA147 (member of the Staphylococcus aureus complex), a non-invasive clinical S. aureus isolate SA303 and a non-invasive Staphylococcus lugdunensis HD1 (coagulase-negative Staphylococcus). (A) overview of the IL-6 response and (B) IL-8 response in a co-culture set-up at MOI 10 and MOI 100, including the four isolates used in the initial experiments. (C) Summary of the invasion property (assessed using flow cytometry) quantified as percentage of infected cells (CFSE positive over the gated population). (D) Stimulation with viable bacteria for S. aureus SA303 and S. lugdunensis HD1 at MOI 100 did not significantly induce IL-6, transfection of bacterial RNA induced IL-6 in a dose-dependent manner. RNase A pre-treatment abolished the IL-6 response. Data for IL-8 are included in the Supplementary Figure S9. The RNA-mediated response is non-sequence specific since bacterial RNA from various staphylococci were able to induce the pro-inflammatory response in a similar manner.

\section{DISCUSSION AND CONCLUSION}

The human skin is the outmost barrier of the human body and is exposed to environmental toxins, mechanical stress, pathogens and commensals. Besides providing a robust physical barrier, the skin is equipped to sense and respond to infection and tissue damage. As an immune response towards infections, the skin can initiate immune response to initiate pathogen clearance and to promote tissue regeneration (41). Keratinocytes are regarded as central players in the function as immune sentinels, which communicate and orchestrate $\mathrm{T}$-cell mediated adaptive immune response. Excessive immune response in the skin can result in pathologic inflammatory response, disrupting tissue integrity and impairing the skin's defense mechanisms. Therefore, a homeostatic state needs to be maintained to prevent overwhelming inflammatory response and keratinocytes must be able to distinguish between commensal and invading pathogens. 
A

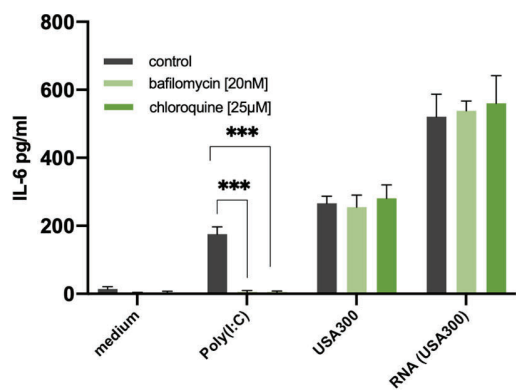

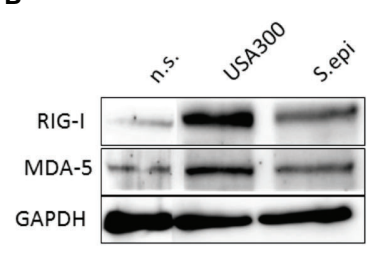

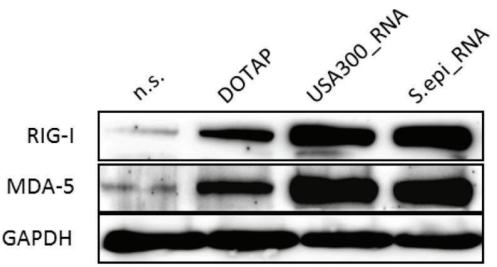

C
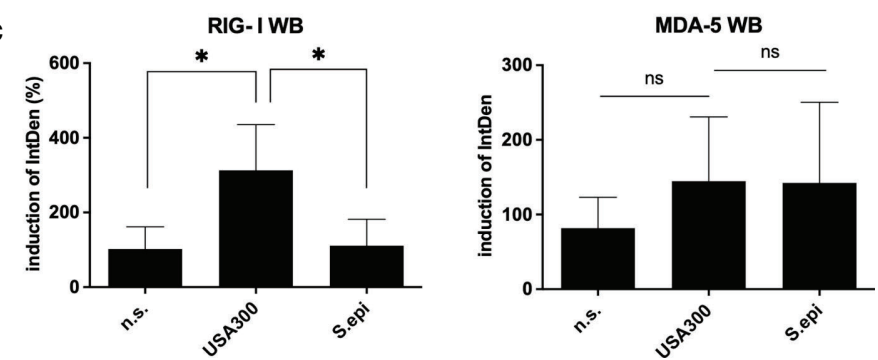

FIGURE 5 | Cytoplasmic RNA sensors may be responsible for the induction of IL-6 by invasive staphylococci. (A) Inhibition with the endosomal TLR inhibitors bafilomycin and chloroquine did not affect the IL-6 response at MOI 100. (B) Both MDA-5 and RIG-I may be involved in the recognition of bacterial RNA following bacterial invasion, as quantified by western blot. Viable S. aureus USA300 induces more RIG-I and MDA5 in keratinocytes compared to viable S. epidermidis at MOI of 100 (B, left panel). Transfection of S. aureus USA300 and S. epidermidis induced similar levels of RIG-I and MDA5 (B, right panel). All experiments were performed as independent experiments in biological triplicates, each in technical duplicates, except for Western Blot (representative of three experiments). (C). Quantification of RIG-I and MDA-5 western blots of keratinocytes stimulated with viable S. aureus and S. epidermidis at MOI of 100. Quantification of protein bands were performed via ImageJ software. Data were analyzed by Graphpad Prism v9 (USA). The IntDen of protein band of interest was divided through IntDen of the respective houskeeping protein band. For calculation of induction mean of data of three unstimulated samples were set to 100 percentage. Statistically significant differences are indicated by ${ }^{*}\left({ }^{*} \mathrm{p}<0.5,{ }^{* \star *} \mathrm{p} \leq 0.001, \mathrm{~ns}\right.$, not significant).

S. aureus and S. epidermidis are perfect model pathogens to study the mechanism by which keratinocytes differentiate between commensal and pathogen. Both $S$. aureus and $S$. epidermidis belong to the genus Staphylococcus and share a certain degree of similarity in the conserved microbial cellular structure. One important difference between $S$. aureus and $S$. epidermidis is their ability to invade cells and survive intracellularly. This suggests that intracellular sensing may play an important role in the sensing and differentiation of commensal and pathogenic staphylococci in keratinocytes. Indeed, our data strongly suggest that keratinocytes are activated in response to $S$. aureus invasion through an intracellular RNA-recognition mechanism.

The sensing of bacterial RNA has been attributed to the ability of the immune systems to detect and respond to microbial viability (42). To our knowledge, it is unclear whether keratinocytes can distinguish between viable or non-viable bacterial cells. In our experimental set-up, heat-inactivated bacteria were not able to induce significant IL-6 or IL-8 response, suggesting that bacterial viability is important for internalization/invasion, which in turn induces pro-inflammatory response in keratinocytes. The role of intracellular RNA receptors in differentiating between viable and dead pathogens has been demonstrated for other bacteria and fungi (43-45). Innate immune cells can detect bacterial mRNA, common to all bacteria, to initiate an immune response $(46,47)$. These bacterial mRNA are considered as the signature of microbial viability and are often classified as a special class of pathogenassociated molecular pattern (PAMP), called vita-PAMPs (47).
Although the role of vita-PAMPs has been studied for other Gram-positive bacteria, such as Streptococcus pyogenes $(42,48)$, the role of bacterial mRNA sensing for $S$. aureus has not been explored.

In our experiments, we observed differences in the secreted IL6 and IL-8 levels, which correlated with the internalization of staphylococci. Although the exact roles of IL-6 and IL-8 in terms of cutaneous defense are not yet fully elucidated, IL-6 and IL-8 have been found to contribute to local wound healing for their ability to promote migration and proliferation of keratinocytes $(49,50)$. Moreover, IL-6 might prevent $S$. aureus from spreading to yet unaffected healthy host cells by promoting keratinocyte differentiation and thus, accelerate the disposal of already infected and surrounding tissue $(51,52)$. During differentiation, infected cells undergo cell death, migrate to the upper layers of the epidermis and eventually, form a cornified barrier (53), which is beneficial considering that $S$. aureus usually requires lesion in the epithelial barrier as a port of entry for infection (54). In contrast to other findings, although the cell line used in our experiments express TLR2, we did not see a strong induction of TLR2-mediated response through secreted mediators, which have been demonstrated in experiments using primary keratinocytes by other groups (1). Although we do not have any definitive explanation for this discrepancy, differences in the TLR2 expression due to differentiation state of the cells or culture conditions (removal of cellular debris by centrifugation and sterile filtering of the supernatant) may have an influence on the expression of PRR in keratinocytes. 
The role of IL- 6 in the pathophysiology of the skin has been extensively investigated. IL- 6 deficiency has been attributed to exacerbation of skin inflammation in an in vivo murine model (55). Furthermore, lower levels of IL-6 in the skin have been linked to exacerbation of atopic dermatitis, a skin condition associated with a propensity for $S$. aureus colonization and infections. On the other hand, patients with psoriasis are less susceptible to $S$. aureus infections, and elevated IL-6 levels have been associated with this skin condition and may be a potential target for psoriasis therapy (56-59). IL-6 also performs an important function in the immunological function of the skin by linking the innate to the acquired immune response $(60,61)$.

IL-8 is involved in recruitments of immune cells to initiate and process further inflammatory response cascade. Indeed, many immune cells, such as neutrophils, T lymphocytes, mast cells, dermal macrophages, endothelial cells and keratinocytes possess IL-8 binding sites (62). The chemotactic properties have been attributed to certain processes, such as cell migration and wound healing (50). Numerous studies have shown that infection of keratinocytes with $S$. aureus induce IL-8 $(63,64)$. In a murine model, IL- 8 has been demonstrated to be important in neutrophil recruitment, which is essential for bacterial clearing in the context of S. aureus colonization/infection (65).Our findings may be relevant to understand the host-bacterial interaction, which may play a role in establishing $S$. aureus colonization. Our previous studies demonstrated that $S$. aureus persistent carriers expressed less antimicrobial peptides than non-carriers, specifically hBD-3, and that this phenotype was linked with genetic polymorphisms in the DEFB1 gene $(8,9)$. In addition, the Th1/Th17-mediated immune response in whole blood was less profound in $S$. aureus persistent carriers than in non-carriers following ex vivo stimulation with viable $S$. aureus (11). However, it is unclear how the immune system of the skin differentiates between commensal and pathogenic bacteria. In this study, we could demonstrate that only $S$. aureus induces pro-inflammatory response in keratinocytes. Together with our previous finding, this study adds to the body of evidence that immunological processes and bacterial-host interaction play an important role in the pathophysiology of $S$. aureus colonization.

Our study has limitations; the study was conducted in an in vitro setting, so that in vivo validation is still needed. The experiments were conducted using an immortalized keratinocyte cell line. We chose this experimental set-up (using a characterized cell line) to ensure comparability between results as the genetic background of keratinocyte donors may influence the immunological function (9). In our experiments, we did not see a strong induction of TLR2-mediated immune response by $S$. aureus USA300, although $\mathrm{HaCaT}$ keratinocyte has been shown to express and react to TLR2 (1). The expression of TLR2 may be lower in this cell lines than primary keratinocytes and validation studies with other cell types and primary cells are necessary to verify our findings. In our experimental set-up, only several bacterial isolates were used, and species heterogeneity was not investigated. Therefore, our data should be interpreted carefully and further validatory experiments are necessary to verify the generalizability of our findings. Nonetheless, our study investigated the host-bacteria interaction using viable bacteria instead of inactivated bacterial cells. As demonstrated, heatkilled bacteria may not be suitable to study host-pathogen interaction since dead bacteria may not express specific proteins, which may be relevant in the overall immunological context.

In the past, keratinocytes were mainly considered as a physical barrier rather than active participants of the immune system. Our data imply that keratinocytes respond differentially to invasive and non-invasive pathogens of the skin. This effect is not specific for a single pathogen but rather non-specific and is mediated via "invasion" of bacterial RNA into the intracellular compartment. Furthermore, this study demonstrated that noninvasive staphylococci do not induce a profound proinflammatory reaction, which may be necessary to promote bacterial elimination and allow these bacteria to colonize the skin as commensals.

\section{DATA AVAILABILITY STATEMENT}

The original contributions presented in the study are included in the article/Supplementary Material. Further inquiries can be directed to the corresponding author.

\section{AUTHOR CONTRIBUTIONS}

QN, AS, KH, and DN conceived and planned the experiments. $\mathrm{QN}, \mathrm{LF}$, and AS performed the experiments. QN, AS, and DN analyzed the experiments. $\mathrm{KH}$ and TE contributed to the interpretation of the results. QN, DH, and $\mathrm{DN}$ drafted and finalized the manuscript. All authors provided critical feedback and contributed to the final manuscript. All authors approved the final submitted version of the manuscript.

\section{FUNDING}

This study was supported by a grant number: 80295MDQUN/ TI07.003_Ngo (MD stipend) from the German Center for Infection Research (DZIF) for QN with $\mathrm{KH}$ and $\mathrm{DN}$ as supervisor for this funded research project.

\section{ACKNOWLEDGMENTS}

We would like to thank Frieder Schaumburg (Institute of Medical Microbiology, University Hospital Münster, Germany) for providing us with the $S$. aureus isolates 8325-4 and DU5883.

\section{SUPPLEMENTARY MATERIAL}

The Supplementary Material for this article can be found online at: https://www.frontiersin.org/articles/10.3389/fimmu.2022. 828626/full\#supplementary-material 


\section{REFERENCES}

1. Kollisch G, Kalali BN, Voelcker V, Wallich R, Behrendt H, Ring J, et al. Various Members of the Toll-Like Receptor Family Contribute to the Innate Immune Response of Human Epidermal Keratinocytes. Immunology (2005) 114:531-41. doi: 10.1111/j.1365-2567.2005.02122.x

2. Lebre MC, van der Aar AM, Van Baarsen L, Van Capel TM, Schuitemaker JH, Kapsenberg ML, et al. Human Keratinocytes Express Functional Toll-Like Receptor 3, 4, 5, and 9. J Invest Dermatol (2007) 127:331-41. doi: 10.1038/ sj.jid. 5700530

3. Wertheim HF, Melles DC, Vos MC, Van Leeuwen W, Van Belkum A, Verbrugh HA, et al. The Role of Nasal Carriage in Staphylococcus Aureus Infections. Lancet Infect Dis (2005) 5:751-62. doi: 10.1016/S1473-3099(05) 70295-4

4. Nouwen JL, Ott A, Kluytmans-Vandenbergh MF, Boelens HA, Hofman A, Van Belkum A, et al. Predicting the Staphylococcus Aureus Nasal Carrier State: Derivation and Validation of a "Culture Rule". Clin Infect Dis (2004) 39:806-11. doi: 10.1086/423376

5. O'brien LM, Walsh EJ, Massey RC, Peacock SJ, Foster TJ. Staphylococcus Aureus Clumping Factor B (ClfB) Promotes Adherence to Human Type I Cytokeratin 10: Implications for Nasal Colonization. Cell Microbiol (2002) 4:759-70. doi: 10.1046/j.1462-5822.2002.00231.x

6. Liu CM, Price LB, Hungate BA, Abraham AG, Larsen LA, Christensen K, et al. Staphylococcus Aureus and the Ecology of the Nasal Microbiome. Sci Adv (2015) 1:e1400216. doi: 10.1126/sciadv.1400216

7. Zipperer A, Konnerth MC, Laux C, Berscheid A, Janek D, Weidenmaier C, et al. Human Commensals Producing a Novel Antibiotic Impair Pathogen Colonization. Nature (2016) 535:511-6. doi: 10.1038/nature18634

8. Zanger P, Nurjadi D, Vath B, Kremsner PG. Persistent Nasal Carriage of Staphylococcus Aureus is Associated With Deficient Induction of Human Beta-Defensin 3 After Sterile Wounding of Healthy Skin In Vivo. Infect Immun (2011) 79:2658-62. doi: 10.1128/IAI.00101-11

9. Nurjadi D, Herrmann E, Hinderberger I, Zanger P. Impaired Beta-Defensin Expression in Human Skin Links DEFB1 Promoter Polymorphisms With Persistent Staphylococcus Aureus Nasal Carriage. J Infect Dis (2013) 207:66674. doi: 10.1093/infdis/jis735

10. Brown AF, Leech JM, Rogers TR, Mcloughlin RM. Staphylococcus Aureus Colonization: Modulation of Host Immune Response and Impact on Human Vaccine Design. Front Immunol (2014) 4:507. doi: 10.3389/fimmu.2013.00507

11. Nurjadi D, Kain M, Marcinek P, Gaile M, Heeg K, Zanger P. Ratio of T-Helper Type 1 (Th1) to Th17 Cytokines in Whole Blood Is Associated With Human Beta-Defensin 3 Expression in Skin and Persistent Staphylococcus Aureus Nasal Carriage. J Infect Dis (2016) 214:1744-51. doi: 10.1093/infdis/jiw440

12. Nurjadi D, Heeg K, Weber ANR, Zanger P. Toll-Like Receptor 9 (TLR-9) Promotor Polymorphisms and Gene Expression are Associated With Persistent Staphylococcus Aureus Nasal Carriage. Clin Microbiol Infect (2018) 24:1210.e1217-1210.e1212. doi: 10.1016/j.cmi.2018.02.014

13. Bitschar K, Staudenmaier L, Klink L, Focken J, Sauer B, Fehrenbacher B, et al. Staphylococcus Aureus Skin Colonization Is Enhanced by the Interaction of Neutrophil Extracellular Traps With Keratinocytes. J Invest Dermatol (2020) 140:1054-65.e1054. doi: 10.1016/j.jid.2019.10.017

14. Becker K, Heilmann C, Peters G. Coagulase-Negative Staphylococci. Clin Microbiol Rev (2014) 27:870-926. doi: 10.1128/CMR.00109-13

15. Foster TJ. Surface Proteins of Staphylococcus Epidermidis. Front Microbiol (2020) 11:1829. doi: 10.3389/fmicb.2020.01829

16. Dziarski R, Wang Q, Miyake K, Kirschning CJ, Gupta D. MD-2 Enables TollLike Receptor 2 (TLR2)-Mediated Responses to Lipopolysaccharide and Enhances TLR2-Mediated Responses to Gram-Positive and Gram-Negative Bacteria and Their Cell Wall Components. J Immunol (2001) 166:1938-44. doi: 10.4049/jimmunol.166.3.1938

17. Fujita M, Into T, Yasuda M, Okusawa T, Hamahira S, Kuroki Y, et al. Involvement of Leucine Residues at Positions 107, 112, and 115 in a Leucine-Rich Repeat Motif of Human Toll-Like Receptor 2 in the Recognition of Diacylated Lipoproteins and Lipopeptides and Staphylococcus Aureus Peptidoglycans. J Immunol (2003) 171:3675-83. doi: 10.4049/jimmunol.171.7.3675

18. Fournier B, Philpott DJ. Recognition of Staphylococcus Aureus by the Innate Immune System. Clin Microbiol Rev (2005) 18:521-40. doi: 10.1128/ CMR.18.3.521-540.2005
19. Lai Y, Cogen AL, Radek KA, Park HJ, Macleod DT, Leichtle A, et al. Activation of TLR2 by a Small Molecule Produced by Staphylococcus Epidermidis Increases Antimicrobial Defense Against Bacterial Skin Infections. J Invest Dermatol (2010) 130:2211-21. doi: 10.1038/jid.2010.123

20. Hanzelmann D, Joo HS, Franz-Wachtel M, Hertlein T, Stevanovic S, Macek B, et al. Toll-Like Receptor 2 Activation Depends on Lipopeptide Shedding by Bacterial Surfactants. Nat Commun (2016) 7:12304. doi: 10.1038/ ncomms12304

21. Queck SY, Khan BA, Wang R, Bach TH, Kretschmer D, Chen L, et al. Mobile Genetic Element-Encoded Cytolysin Connects Virulence to Methicillin Resistance in MRSA. PLoS Pathog (2009) 5:e1000533. doi: 10.1371/ journal.ppat.1000533

22. Sendi P, Proctor RA. Staphylococcus Aureus as an Intracellular Pathogen: The Role of Small Colony Variants. Trends Microbiol (2009) 17:54-8. doi: 10.1016/ j.tim.2008.11.004

23. Fraunholz M, Sinha B. Intracellular Staphylococcus Aureus: Live-in and Let Die. Front Cell Infect Microbiol (2012) 2:43. doi: 10.3389/fcimb.2012.00043

24. Hanssen AM, Kindlund B, Stenklev NC, Furberg AS, Fismen S, Olsen RS, et al. Localization of Staphylococcus Aureus in Tissue From the Nasal Vestibule in Healthy Carriers. BMC Microbiol (2017) 17:89. doi: 10.1186/s12866-0170997-3

25. Abu-Humaidan AH, Elven M, Sonesson A, Garred P, Sorensen OE. Persistent Intracellular Staphylococcus Aureus in Keratinocytes Lead to Activation of the Complement System With Subsequent Reduction in the Intracellular Bacterial Load. Front Immunol (2018) 9:396. doi: 10.3389/fimmu.2018.00396

26. Al Kindi A, Alkahtani AM, Nalubega M, El-Chami C, O'neill C, Arkwright PD, et al. Staphylococcus Aureus Internalized by Skin Keratinocytes Evade Antibiotic Killing. Front Microbiol (2019) 10:2242. doi: 10.3389/ fmicb.2019.02242

27. Roth SA, Simanski M, Rademacher F, Schroder L, Harder J. The Pattern Recognition Receptor NOD2 Mediates Staphylococcus Aureus-Induced IL17C Expression in Keratinocytes. J Invest Dermatol (2014) 134:374-80. doi: 10.1038/jid.2013.313

28. Hruz P, Zinkernagel AS, Jenikova G, Botwin GJ, Hugot JP, Karin M, et al. NOD2 Contributes to Cutaneous Defense Against Staphylococcus Aureus Through Alpha-Toxin-Dependent Innate Immune Activation. Proc Natl Acad Sci U S A (2009) 106:12873-8. doi: 10.1073/pnas.0904958106

29. Sinha B, Francois PP, Nusse O, Foti M, Hartford OM, Vaudaux P, et al. Fibronectin-Binding Protein Acts as Staphylococcus Aureus Invasin via Fibronectin Bridging to Integrin Alpha5beta1. Cell Microbiol (1999) 1:10117. doi: 10.1046/j.1462-5822.1999.00011.x

30. Haglund CM, Welch MD. Pathogens and Polymers: Microbe-Host Interactions Illuminate the Cytoskeleton. J Cell Biol (2011) 195:7-17. doi $10.1083 /$ jcb. 201103148

31. Marks DC, Belov L, Davey MW, Davey RA, Kidman AD. The MTT Cell Viability Assay for Cytotoxicity Testing in Multidrug-Resistant Human Leukemic Cells. Leuk Res (1992) 16:1165-73. doi: 10.1016/0145-2126(92) 90114-M

32. Dalpke A, Frank J, Peter M, Heeg K. Activation of Toll-Like Receptor 9 by DNA From Different Bacterial Species. Infect Immun (2006) 74:940-6. doi: 10.1128/IAI.74.2.940-946.2006

33. Ohto U, Shibata T, Tanji H, Ishida H, Krayukhina E, Uchiyama S, et al. Structural Basis of CpG and Inhibitory DNA Recognition by Toll-Like Receptor 9. Nature (2015) 520:702-5. doi: 10.1038/nature14138

34. Leonard JN, Ghirlando R, Askins J, Bell JK, Margulies DH, Davies DR, et al. The TLR3 Signaling Complex Forms by Cooperative Receptor Dimerization. Proc Natl Acad Sci U S A (2008) 105:258-63. doi: 10.1073/pnas.0710779105

35. Diebold SS, Kaisho T, Hemmi H, Akira S, Reis E Sousa C. Innate Antiviral Responses by Means of TLR7-Mediated Recognition of Single-Stranded RNA. Science (2004) 303:1529-31. doi: 10.1126/science.1093616

36. Yoneyama M, Onomoto K, Jogi M, Akaboshi T, Fujita T. Viral RNA Detection by RIG-I-Like Receptors. Curr Opin Immunol (2015) 32:48-53. doi: 10.1016/ j.coi.2014.12.012

37. Tong SYC, Schaumburg F, Ellington MJ, Corander J, Pichon B, Leendertz F, et al. Novel Staphylococcal Species That Form Part of a Staphylococcus Aureus-Related Complex: The Non-Pigmented Staphylococcus Argenteus Sp. Nov. And the Non-Human Primate-Associated Staphylococcus Schweitzeri Sp. Nov. Int J Syst Evol Microbiol (2015) 65:15-22. doi: 10.1099/ijs.0.062752-0 
38. Becker K, Schaumburg F, Kearns A, Larsen AR, Lindsay JA, Skov RL, et al. Implications of Identifying the Recently Defined Members of the Staphylococcus Aureus Complex S. Argenteus and S. Schweitzeri: A Position Paper of Members of the ESCMID Study Group for Staphylococci and Staphylococcal Diseases (ESGS). Clin Microbiol Infect (2019) 25:1064-70. doi: 10.1016/j.cmi.2019.02.028

39. Parthasarathy S, Shah S, Raja Sager A, Rangan A, Durugu S. Staphylococcus Lugdunensis: Review of Epidemiology, Complications, and Treatment. Cureus (2020) 12:e8801. doi: 10.7759/cureus.8801

40. Kuznik A, Bencina M, Svajger U, Jeras M, Rozman B, Jerala R. Mechanism of Endosomal TLR Inhibition by Antimalarial Drugs and Imidazoquinolines. J Immunol (2011) 186:4794-804. doi: 10.4049/jimmunol.1000702

41. Klicznik MM, Szenes-Nagy AB, Campbell DJ, Gratz IK. Taking the Lead How Keratinocytes Orchestrate Skin T Cell Immunity. Immunol Lett (2018) 200:43-51. doi: 10.1016/j.imlet.2018.06.009

42. Sander LE, Davis MJ, Boekschoten MV, Amsen D, Dascher CC, Ryffel B, et al. Detection of Prokaryotic mRNA Signifies Microbial Viability and Promotes Immunity. Nature (2011) 474:385-9. doi: 10.1038/nature10072

43. Simonov D, Swift S, Blenkiron C, Phillips AR. Bacterial RNA as a Signal to Eukaryotic Cells as Part of the Infection Process. Discover (Craiova) (2016) 4: e70. doi: 10.15190/d.2016.17

44. Ugolini M, Gerhard J, Burkert S, Jensen KJ, Georg P, Ebner F, et al. Recognition of Microbial Viability via TLR8 Drives TFH Cell Differentiation and Vaccine Responses. Nat Immunol (2018) 19:386-96. doi: 10.1038/s41590-018-0068-4

45. Wang X, Caffrey-Carr AK, Liu KW, Espinosa V, Croteau W, Dhingra S, et al. MDA5 Is an Essential Sensor of a Pathogen-Associated Molecular Pattern Associated With Vitality That Is Necessary for Host Resistance Against Aspergillus Fumigatus. J Immunol (2020) 205:3058-70. doi: 10.4049/ jimmunol.2000802

46. Mourao-Sa D, Roy S, Blander JM. Vita-PAMPs: Signatures of Microbial Viability. Adv Exp Med Biol (2013) 785:1-8. doi: 10.1007/978-1-4614-6217-0_1

47. Hayward JA, Mathur A, Ngo C, Man SM. Cytosolic Recognition of Microbes and Pathogens: Inflammasomes in Action. Microbiol Mol Biol Rev (2018) 82: e00015-18. doi: 10.1128/MMBR.00015-18

48. Hafner A, Kolbe U, Freund I, Castiglia V, Kovarik P, Poth T, et al. Crucial Role of Nucleic Acid Sensing via Endosomal Toll-Like Receptors for the Defense of Streptococcus Pyogenes In Vitro and In Vivo. Front Immunol (2019) 10:198. doi: 10.3389/fimmu.2019.00198

49. Lin ZQ, Kondo T, Ishida Y, Takayasu T, Mukaida N. Essential Involvement of IL-6 in the Skin Wound-Healing Process as Evidenced by Delayed Wound Healing in IL-6-Deficient Mice. J Leukoc Biol (2003) 73:713-21. doi: 10.1189/ jlb.0802397

50. Takada K, Komine-Aizawa S, Hirohata N, Trinh QD, Nishina A, Kimura H, et al. Poly I:C Induces Collective Migration of HaCaT Keratinocytes via IL-8. BMC Immunol (2017) 18:19. doi: 10.1186/s12865-017-0202-3

51. Frank S, Madlener M, Werner S. Transforming Growth Factors Beta1, Beta2, and Beta3 and Their Receptors are Differentially Regulated During Normal and Impaired Wound Healing. J Biol Chem (1996) 271:10188-93. doi: 10.1074/jbc.271.17.10188

52. Luckett-Chastain LR, Cottrell ML, Kawar BM, Ihnat MA, Gallucci RM. Interleukin (IL)-6 Modulates Transforming Growth Factor-Beta Receptor I and II (TGF-betaRI and II) Function in Epidermal Keratinocytes. Exp Dermatol (2017) 26:697-704. doi: 10.1111/exd.13260

53. Turksen K, Kupper T, Degenstein L, Williams I, Fuchs E. Interleukin 6: Insights to its Function in Skin by Overexpression in Transgenic Mice. Proc Natl Acad Sci U S A (1992) 89:5068-72. doi: 10.1073/pnas.89.11.5068

54. Nurjadi D, Friedrich-Janicke B, Schafer J, Van Genderen PJ, Goorhuis A, Perignon A, et al. Skin and Soft Tissue Infections in Intercontinental
Travellers and the Import of Multi-Resistant Staphylococcus Aureus to Europe. Clin Microbiol Infect (2015) 21:567.e561-510. doi: 10.1016/ j.cmi.2015.01.016

55. Lee EG, Mickle-Kawar BM, Gallucci RM. IL-6 Deficiency Exacerbates Skin Inflammation in a Murine Model of Irritant Dermatitis. J Immunotoxicol (2013) 10:192-200. doi: 10.3109/1547691X.2012.707700

56. Christophers E, Henseler T. Contrasting Disease Patterns in Psoriasis and Atopic Dermatitis. Arch Dermatol Res (1987) 279 Suppl:S48-51. doi: 10.1007/ BF00585919

57. Grossman RM, Krueger J, Yourish D, Granelli-Piperno A, Murphy DP, May LT, et al. Interleukin 6 is Expressed in High Levels in Psoriatic Skin and Stimulates Proliferation of Cultured Human Keratinocytes. Proc Natl Acad Sci U S A (1989) 86:6367-71. doi: 10.1073/pnas.86.16.6367

58. Goodman WA, Levine AD, Massari JV, Sugiyama H, Mccormick TS, Cooper KD. IL-6 Signaling in Psoriasis Prevents Immune Suppression by Regulatory T Cells. J Immunol (2009) 183:3170-6. doi: 10.4049/jimmunol.0803721

59. Croxford AL, Karbach S, Kurschus FC, Wortge S, Nikolaev A, Yogev N, et al. IL-6 Regulates Neutrophil Microabscess Formation in IL-17A-Driven Psoriasiform Lesions. J Invest Dermatol (2014) 134:728-35. doi: 10.1038/ jid.2013.404

60. Ivanov II, Mckenzie BS, Zhou L, Tadokoro CE, Lepelley A, Lafaille JJ, et al. The Orphan Nuclear Receptor RORgammat Directs the Differentiation Program of Proinflammatory IL-17+ T Helper Cells. Cell (2006) 126:112133. doi: $10.1016 /$ j.cell.2006.07.035

61. Korn T, Bettelli E, Oukka M, Kuchroo VK. IL-17 and Th17 Cells. Annu Rev Immunol (2009) 27:485-517. doi: 10.1146/annurev.immunol.021908.132710

62. Jiang WG, Sanders AJ, Ruge F, Harding KG. Influence of Interleukin-8 (IL-8) and IL-8 Receptors on the Migration of Human Keratinocytes, the Role of PLC-Gamma and Potential Clinical Implications. Exp Ther Med (2012) 3:231-6. doi: 10.3892/etm.2011.402

63. Sasaki T, Kano R, Sato H, Nakamura Y, Watanabe S, Hasegawa A. Effects of Staphylococci on Cytokine Production From Human Keratinocytes. $\mathrm{Br} J$ Dermatol (2003) 148:46-50. doi: 10.1046/j.1365-2133.2003.05017.x

64. Olaru F, Jensen LE. Staphylococcus Aureus Stimulates Neutrophil Targeting Chemokine Expression in Keratinocytes Through an Autocrine IL-1alpha Signaling Loop. J Invest Dermatol (2010) 130:1866-76. doi: 10.1038/ jid.2010.37

65. Schulz A, Jiang L, De Vor L, Ehrstrom M, Wermeling F, Eidsmo L, et al Neutrophil Recruitment to Noninvasive MRSA at the Stratum Corneum of Human Skin Mediates Transient Colonization. Cell Rep (2019) 29:107481.e1075. doi: 10.1016/j.celrep.2019.09.055

Conflict of Interest: The authors declare that the research was conducted in the absence of any commercial or financial relationships that could be construed as a potential conflict of interest.

Publisher's Note: All claims expressed in this article are solely those of the authors and do not necessarily represent those of their affiliated organizations, or those of the publisher, the editors and the reviewers. Any product that may be evaluated in this article, or claim that may be made by its manufacturer, is not guaranteed or endorsed by the publisher.

Copyright () 2022 Ngo, Faass, Sähr, Hildebrand, Eigenbrod, Heeg and Nurjadi. This is an open-access article distributed under the terms of the Creative Commons Attribution License (CC BY). The use, distribution or reproduction in other forums is permitted, provided the original author(s) and the copyright owner(s) are credited and that the original publication in this journal is cited, in accordance with accepted academic practice. No use, distribution or reproduction is permitted which does not comply with these terms. 